\title{
Review
}

\section{Evaluation of gene flow and its environmental effects in the field}

\author{
Mikihisa Umehara', Ikue Eguchi², Daisuke Kaneko ${ }^{3}$, Michiyuki Ono $^{3 *}$, \\ Hiroshi Kamada ${ }^{3}$ \\ ${ }^{1}$ Department of Biotechnology, Fukuoka Agricultural Research Center, Yoshiki 587, Chikushino, Fukuoka 818-8549, \\ Japan; ${ }^{2}$ Agriculture Extension Center of Bando, Iwai 5205-3, Bando, Ibaraki 306-0631, Japan; ${ }^{3}$ Gene Research \\ Center, University of Tsukuba, Tsukuba, Ibaraki 305-8572, Japan \\ *E-mail: miono@sakura.cc.tsukuba.ac.jp Tel: +81-29-853-7759 Fax: +81-29-853-7746
}

Received September 2, 2005; accepted October 14, 2005 (Edited by H. Morikawa)

\begin{abstract}
To establish a guideline for assessing the environmental effects of genetically modified (GM) crops, flows of genes from GM crops to their wild relatives should be understood. We investigated the gene flow between cultivated and wild varieties of carrot, Daucus carota, as a model plant system despite of the fact that no GM carrot is currently cultivated in Japan. Carrot is one of most widely cultivated vegetables and shows high genetic diversity because of its cross- and insect-mediated-pollination characteristics. Since wild carrot grows in many countries including Japan, gene flow in carrot would be one of the worst cases of dispersing unnecessary modified genes to the wild. In this study, we investigated the population density of wild carrot in Hokkaido, Japan, and the behaviors of its pollinators. There, wild carrot grows in wasteland and along roads near the coast where cultivated carrot cannot grow. We made hybrids between wild and cultivated carrots, observed their growth, and found that the hybrid could vigorously grow at the site. We also found gene markers that can distinguish wild carrot from its cultivated relative although the wild carrot population was more genetically diverse than the cultivated one. These makers will enable gene introgression from cultivated carrot to its wild relatives to be detected. This study will be a reference for assessing gene flows in GM crops.
\end{abstract}

Key words: Daucus carota, environmental assessment, gene diversity, gene flow, genetically modified crops.

Along with the development of plant biotechnology, various GM plants have been produced. Gene engineering is expected to realize "dream plants", which will provide useful tools for medical science and solve environmental and food problems. Despite of the potential benefits of GM crops, some consuming public is concerned about the adverse effects of GM crops on the environment such as putative invasiveness, vertical or horizontal gene flow, reduction of gene diversity, and impacts on other crops (Shelton and Sears 2001; Perlak et al. 2001; Conner et al. 2003; Nap et al. 2003). Of these, gene flows from GM crops to their wild relatives are today's most concerned topic (Snow et al. 1997). For example, an inaccurate report on the introgression of transgene from GM maize to traditional maize in Mexico gave a shock to the entire world (Quist et al. 2001). In order to minimize the potential environmental effects of GM plants on the gene diversity of their relatives, the Cartagena Protocol was established (https: //www.biodiv.org/doc/legal/cartagena-protocol-en.pdf). However, environmental effects of GM crops are not yet thoroughly understood. Potential environmental effects of GM crops should be investigated and an appropriate guideline for assessing GM crops should be established to commercialize GM crops.

The process of gene flow consists of several steps (Figure 1). When GM crops are cultivated in areas where their wild relatives grow, GM crops possibly cross with the wide relatives. When the resultant hybrids grow and develop flowers in the field, introgression into the wild occurs. Therefore, the effects of gene flow on gene diversity must be investigated for certain crops. Growing GM crops in research fields would have facilitated our study on the effects on gene diversity of their wild relatives. However, in Japan, only some GM crops, such as rape seed (Brassica napus L.), soybean (Glycine max L.) and maize (Zea mays L.) are allowed to be cultivated in test fields, and these are not suitable for our study because they either have no wild relatives or are little possible to hybridize with the wild relatives.

Carrot (Daucus carota L.) is one of the most widely cultivated vegetables in the world. Cultivated carrot has a wild relative, which is called wild carrot. The shape of a wild carrot is very similar to that of cultivated varieties except for the taproot (Dale et al. 1974; Wijnheijmer et al. 1989). Wild carrot grows in various areas of the

Abbreviations: AFLP, amplified fragment length polymorphism; GM, genetically modified; HPLC, high-performance liquid chromatography; PCR, polymerase chain reaction; RAPD, randomly amplified polymorphic DNA; RFLP, restriction fragment length polymorphism.

This article can be found at http://www.jspcmb.jp/ 


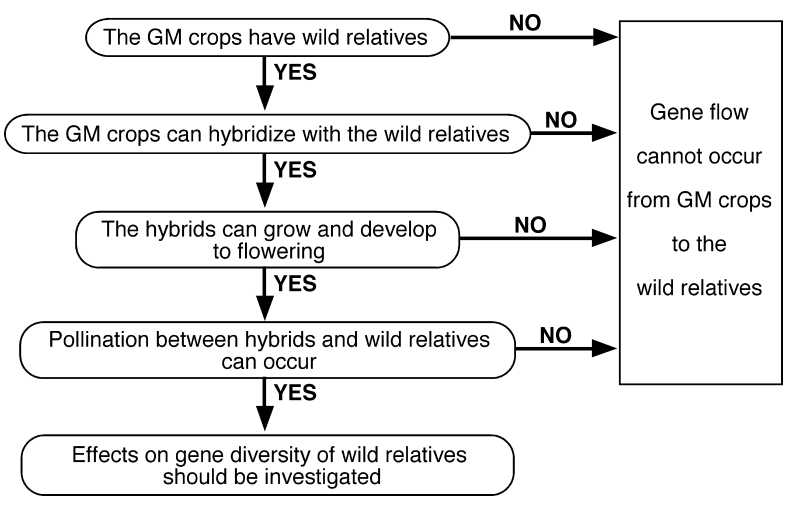

Figure 1. Check points for evaluating the gene flow from GM crops to the wild relatives.

temperate zones of the world (Brandenburg et al. 1981). As carrot has cross- and insect-mediated-pollination characteristics (Borthwick and Emsweller 1933; Thompson 1962), its pattern of gene flow is possibly complicated. Therefore, gene flow in carrot would be one of the worst cases, and carrot should be a model plant appropriate for investigating the effects of gene flow from GM crops on the gene diversity of the wild relative in the field. In this article, we investigated the population density of wild carrot and the behaviors of its pollinators, and established molecular markers for distinguishing wild carrot from cultivated varieties. We also made hybrids between wild and cultivated carrots and observed their growth. This study will be a model for predicting the effects of gene flow.

\section{Characteristics of wild carrot}

Carrot has wild relatives called wild carrot. Leaves and flowers of wild carrot resemble those of cultivated ones but the taproot of wild carrot is thin and white (Figure 3). Wild carrot has been known in Western countries as a weed and researched from the view point of weed (Georgia 1914; Frankton 1970; Sylwester 1960; Stachler and Kells 1997; Stachler et al. 2000). Although wild carrot is a common plant found in various areas of the world, little is known about the plant.

In Hokkaido, Japan, wild carrot growing in the wild was first collected in 1968 (Specimen of the Hokkaido University Museum). In 35 years, the wild carrot spread over almost the entire Hokkaido. Distribution of wild carrot in Oshima Peninsula, the southernmost peninsula of Hokkaido, was investigated in detail (Figure 2A). In Oshima Peninsula, there were several big populations of wild carrot, especially along roads near the coast (Figure 2B) and in sunny wasteland (Figure 2C), where other plants were difficult to grow. Conversely, no big populations of wild carrot were seen in thickly weeded areas, such as on mountainsides.

Using a big population of wild carrot in Matsumae

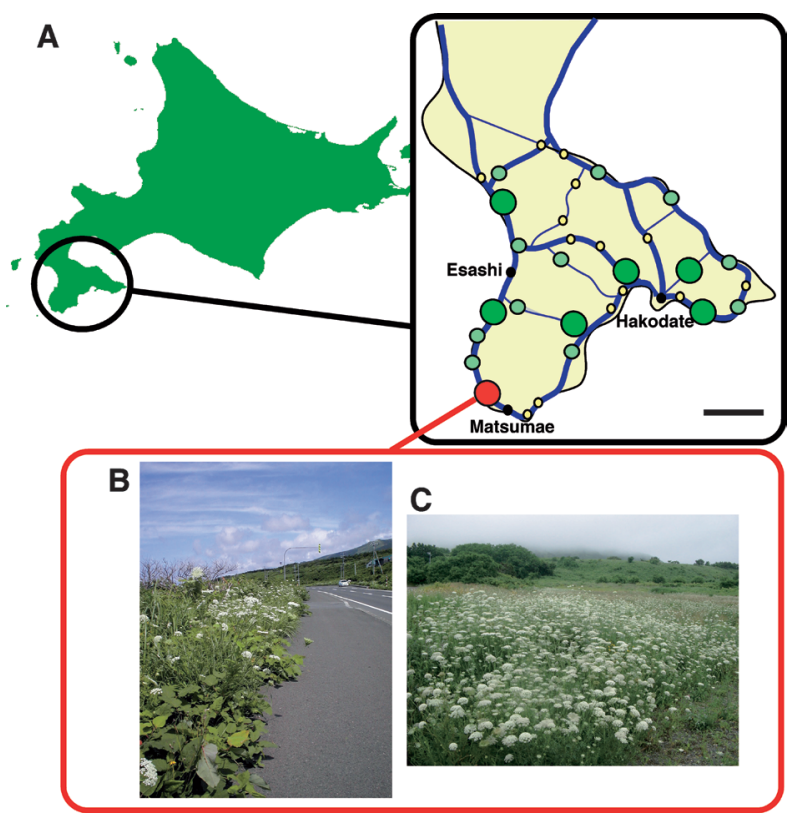

Figure 2. Distribution of wild carrot in Hokkaido, Japan. A. Wild carrot widely distributes in Oshima peninsula. Each green circle shows a population of wild carrot and the size of circles reflects the population size. Yellow circle shows the existence of a separately growing plant. Large populations were found near the coast. Red circle near Matsumae is a main research point. Bar indicates $20 \mathrm{~km}$. B. Wild carrot growing along road near the coast. C. Wild carrot growing in wasteland.

$\left(41^{\circ} 25^{\prime} \mathrm{N}, 140^{\circ} 4^{\prime} \mathrm{E}\right)$, we investigated the transition of population from 2003 to 2004 (Eguchi et al. 2004). In shaded areas, the population density sharply decreased within a year. On the other hand, the population increased in sunny places. Flowering rate was also higher in the sunny places than in the shade. Wild carrot has advanced into areas where no wild carrot was seen few years ago, and germinates under other plants, such as Cirsium vulgare Tenore, Equiseteum arvense L., Hypochoeris radicata L., Picris hieracioides L. var. glabrescens, Rumex obtusufolius L., Sanchus asper Hill and Solidago altissima L.

The correlation between light intensity and population density was investigated by analyzing the growth rate of wild carrot under different illumination conditions (Eguchi et al. 2004). Although germination rate was similar in all conditions, seedlings grown under reduced illumination developed less and shorter leaves than those grown under high illumination.

These results demonstrate that wild carrot prefers sunny areas and areas disturbed by human activities. Therefore, wild carrot has rapidly expanded their habitat in wasteland within two years. In case of carrot, the effects of gene flow from GM plants to their wild relatives are probably very large and should not be ignored. 


\section{Characteristics of hybrid between wild and cultivated carrot}

Cultivated carrot and wild carrot can hybridize with each other (Wijnheijmer et al. 1989). We obtained hybrids between wild and cultivated carrots (cv. USHarumakigosun) by reciprocal crossing. The hybrids showed characteristic taproots, which were yellowish and intermediate of the wild and cultivated carrots in thickness (Figure 3A).

The contents of $\alpha$ - and $\beta$-carotene in the leaves and taproots of cultivated carrot, wild carrot and the hybrid were quantified by HPLC (Figure 3B, C). In the leaves, the cultivated carrot contained less $\beta$-carotene than the wild carrot and the hybrid (Figure 3B). On the other hand, almost no $\alpha$-carotene was detected in the leaves of the wild carrot and the hybrid. Although the total carotene contents in the leaves were similar in all of them, carotene was not detected in the taproots of the wild carrot, and the amount of $\beta$-carotene in the taproot of the hybrid was small (Figure 3C).

To examine whether the cultivated carrot and the hybrid can grow in sunny wasteland or not, seeds of cultivated carrot, wild carrot, and the hybrid were sown in a field (in Matsumae, Hokkaido) where wild carrots grow naturally (data not shown). Seeds of cultivated carrot could germinate as well as those of the others, but the seedlings could not survive because they could not grow roots to penetrate into the firm soil. On the other hand, the seedlings of the hybrid grew and flowered as well as the wild carrot. These results showed that the nature of the hybrid was closer to that of wild carrot than that of cultivated carrot. We concluded that the hybrids could survive and hybridize with wild carrot.

\section{Estimating the distance of gene flow}

The distance of gene flow can be estimated from data of pollen viability and by simulating pollinator behaviors. Viability of wild carrot pollen is investigated by double staining with fluorescein diacetate and propidium iodide (Eguchi et al. 2004). The viability of wild carrot pollen decreased as time passed. Especially during the first $12 \mathrm{~h}$, it decreased sharply from $100 \%$ to $50 \%$. In 10 days after the collection of pollen, it became completely $0 \%$. Thus, the lifetime of these pollens is likely to be shorter than 10 days.

The pollination efficiency and pollinators of carrot have long been investigated from the viewpoint of breeding (Hawthorn et al. 1956; Hawthorn et al. 1960; Bohart and Nye 1960; Peterson and Simon 1986). Although pollination distance has been investigated (Galuszka et al. 1989; Koga and Namai 2001), these studies were conducted in fields of only several square meters. Studies need to be conducted in fields larger than
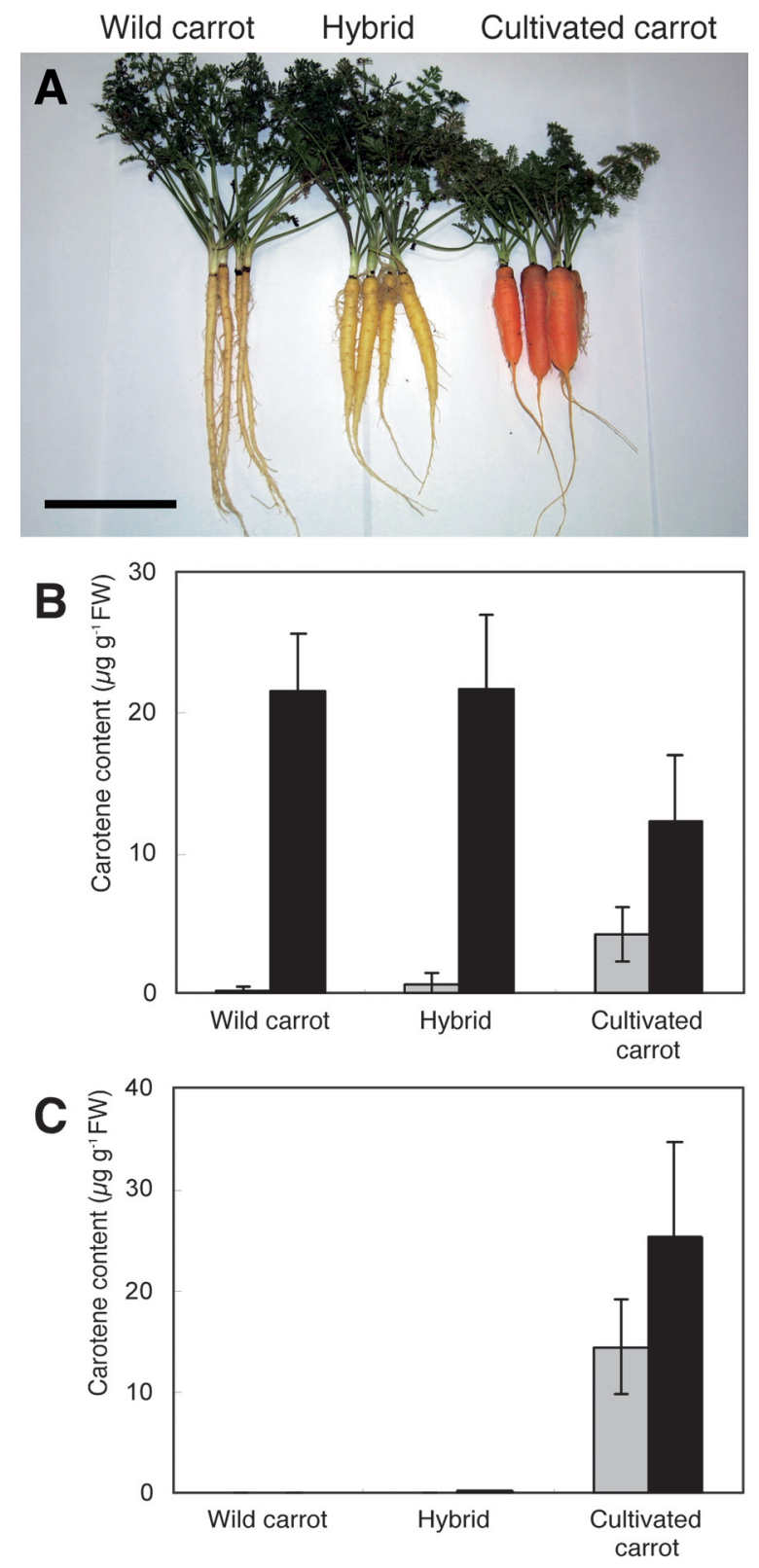

Figure 3. Comparison of morphological trait and carotene content among wild carrot, cultivated carrot and the hybrid. A. Photograph of wild carrot, hybrid, cultivated carrot (left to right). These plants were grown for five months in pots. Bar indicates $5 \mathrm{~cm}$. B. Carotene content in leaves. C. Carotene content in taproot. Gray and black boxes show the contents of $\alpha$ - and $\beta$-carotene, respectively. Error bars represent SD with $\mathrm{n}=6$.

these to estimate the extent of gene flow. The behaviors of pollinator insects in a field of wild carrot was investigated in August, 2003. We observed the pollination activities of hoverflies such as Elistalis tenax L., Metasyrohus ferquens L., Sphaerophoria menthastr L. and Temnostoma apiforme L., flies such as Lucilia caeser L., Musca demestica L. and Ectophasia rotundiventris Loew, bees such as Apis cerana L., and other insects such as Chrysanthia viatica Lewis, Graphosoma nubrolineatum L., Homonotus iwatai 

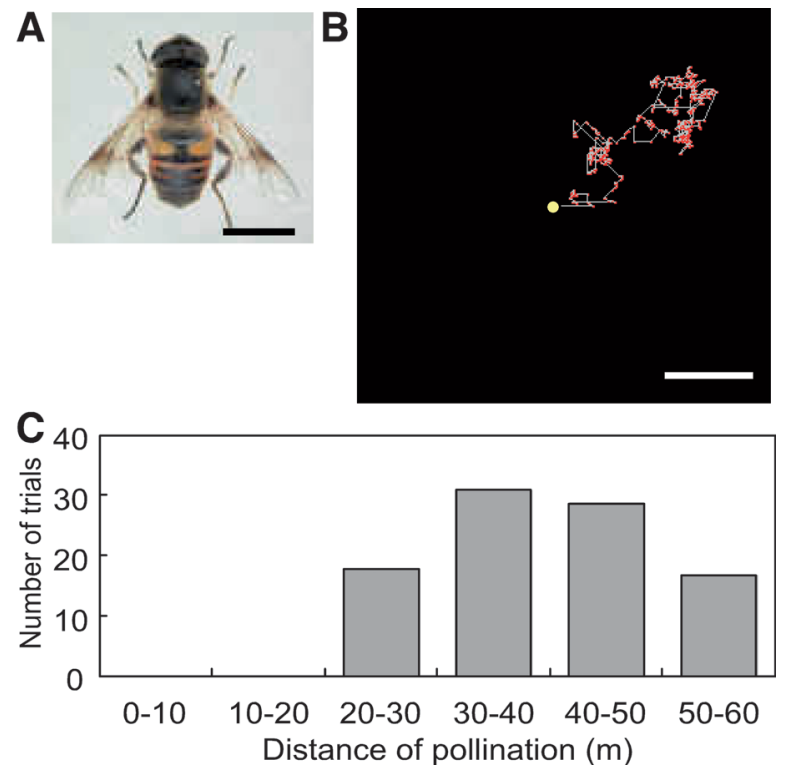

Figure 4. Estimation of the distance of gene flow mediated by hoverflies, Eristalis tenax L. A. Outlook of Eristalis tenax L., the principal pollinator of wild carrot in Matsumae. Bar indicates $5 \mathrm{~mm}$. B. An example of simulated and traced behavior patterns of Eristalis tenax L. White line and red points show tracks of Eristalis tenax L. for $12 \mathrm{~h}$ in the daytime. Yellow circle denotes starting point. Bar indicates $5 \mathrm{~m}$. C. Histogram of the maximum pollination distance mediated by Eristalis tenax L. Vertical axis shows the number of trials.

Yasumatsu and Lasius japonicus L., of which. hoverflies and bees accounted for the majority. Among them, a kind of hoverfly, Eristalis tenax L. (Figure 4A), visited wild carrot flowers most frequently.

Based on the behavior of Eristalis tenax L., the maximum distance of pollination was calculated using the HF ver. 2.1, which is a program developed by Dr. Toquenaga, University of Tsukuba (Figure 4B). Assuming that insects are active during $12 \mathrm{~h}$ a day in summer, E. tenax could have traveled $20-60 \mathrm{~m}$ per day (Figure 4C). Therefore, in a period of 10 days, which is longer than the lifetime of these pollens, the insects could have transported pollens over a distance not longer than $600 \mathrm{~m}$. This is just a mere example because this estimation is only for Eristalis tenax L. Still, the results provide some clues to control gene flows from GM crops to their wild relatives. For example, this approach will be effective to decide the width of buffer zones for trapping pollinators that visited GM crops and prevent pollens from being scattered to wild populations.

Dispersal of seeds can also be a mean of gene flow. Carrot seeds are small and covered with prickles (Figure $5 \mathrm{~A})$. Because of the shape, wild carrot seeds are possibly transported by both wind and animals. Scattering of seeds by wind was investigated using the average wind velocity in September in Matsumae, Hokkaido. The seeds were found to be scattered over a distance not longer than $3.0 \mathrm{~m}$ under the artificial condition of wind velocity of $3 \mathrm{~m} \mathrm{sec}^{-1}$ (Figure 5B). This result agrees with
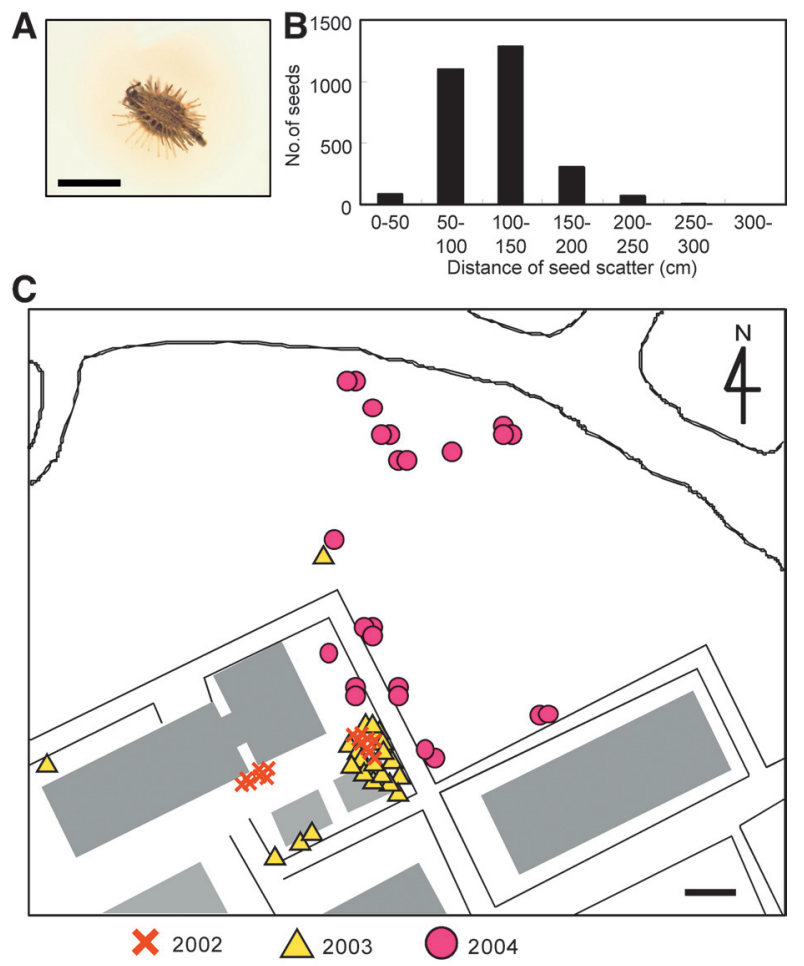

Figure 5. A. Outlook of wild carrot seed. Bar indicates $2 \mathrm{~mm}$. B. Distance of seed scattering measured in wind of $3 \mathrm{~m} \mathrm{sec}^{-1}$ in velocity. C. Distribution of wild carrot near the Gene Research Center, University of Tsukuba, Japan. Crosses, triangles and circles show the existence of wild carrot in 2002, 2003 and 2004, respectively. Gray zone shows building. Bar indicates $10 \mathrm{~m}$.

the spread of recently transplanted wild carrot near the Gene Research Center, University of Tsukuba, Japan. In this area, most wild carrots flowered within several meters from their maternal plants.

However, some wild carrots were found as far as over 10 meters from their maternal plants. In two years, some wild carrot individuals were found ca. $100 \mathrm{~m}$ away from the original area (Figure 5C). Animals and passengers may have carried the seeds because they were found along passages. Because of the seed shape, carrot seeds should be easily carried far by animals. As in the other plants, the distance over which seeds are scattered should differ depending on scattering medium. Therefore, the scattering mechanisms should be investigated for each plant species. This approach was useful for estimating the flow of genes but could not determine the actual distance of gene flow. Yellow taproot of the hybrid is a useful morphological marker (Figure 3A), but gene marker should be a more effective marker for monitoring the flow of genes.

\section{Construction of gene marker to distinguish wild from cultivated carrot}

To investigate the effects of gene flow from cultivated carrot on the gene diversity of its wild relatives, gene 
marker for distinguishing wild from cultivated carrots needs to be constructed. Gene markers have been searched for using various approaches. RAPD analysis is a most handy method used for plants in general (Welsh and McClelland 1990; Williams et al. 1990). Although some primers were reported to be useful in carrot (Nakajima et al. 1998), we could not obtain clear results that distinguished wild from cultivated carrots (data not shown). Moreover, the reproducibility of each fragment was low. RAPD, which has low sensitivity, should be not suitable for interspecies comparison

Microsatellite is also widely used to research gene flow since it has a co-dominant trait. We amplified and sequenced twenty-two microsatellite loci (developed at http://www.uga.edu/srel/Msat_Devmt/Microsatelliteshome.htm). Each microsatellite sequence was compared between wild and cultivated carrots (data not shown). In all microsatellite loci, the length was inconsistent. Microsatellites of the wild carrot were more diverse than those of cultivated carrot. Because most microsatellite loci exist in introns, they are prone to mutations. Therefore, microsatellite markers are suitable for investigating relatively uniform populations such as woody plants (Chase et al. 1996; Streiff et al. 1999; Miyazaki et al. 2000; Isagi et al. 2000), but unsuitable for plants that have highly variable genome, such as carrot.

Another candidate marker is $\mathrm{Y}_{2}$ locus, which controls the carotene accumulation in the root xylem core (Buishand and Gabelman 1979; Simon 1996) and was mapped using AFLP (Braden et al. 1998). Braden et al. also designed primer pairs that can detect the differences in sequence between carrots whose xylem core is yellow and red. Using these primers, we compared the $\mathrm{Y}_{2}$ loci of wild carrot and cultivated carrot (cv. Kurodagosun) that has red xylem core. However, we found that the sequences were completely identical between wild carrot and Kurodagosun (data not shown).

The most remarkable difference between wild and cultivated carrot was the color of taproot (Figure 3A). Cultivated carrot contains high levels of carotene in taproot while the wild carrot has none. It has been reported that the sequences of genes that are involved in carotenoid biosynthesis were different between carrots that contain different levels of carotene (Lipinski et al. 2002). Therefore, three carrot genes, which are involved in carotenoid synthesis, phytoene synthase (PSY), lycopene $\varepsilon$-cyclase $(L C Y B)$ and lycopene $\varepsilon$-cyclase ( $L C Y E)$, were investigated.

In a fragment amplified with primer PSY-847F and PSY-1356R, AvaI site was reported only in wild carrot (Lipinski et al. 2002). However, our result of AvaI digestion showed no consistency (data not shown). Some wild carrots had $A v a \mathrm{I}$ restriction site and the others didn't. Therefore, this fragment was impossible to distinguish wild from cultivated carrots by the band pattern of electrophoresis.

It was also reported that the $\angle C Y B$ allele of highcarotene carrot was restricted by TaqI (Lipinski et al. 2002). However, in both high- and low-carotene groups, some $L C Y B$ fragments were restricted and others were not (data not shown). Therefore, it was again impossible to distinguish wild from cultivated carrot by the band pattern of electrophoresis. Besides, except for the restriction sites, there was no difference in the sequence of $L C Y B$ between the wild and cultivated carrots. As in $L C Y E$, the sequence was completely identical between the wild and cultivated carrots (data not shown).

We investigated the three genes, which are involved in carotenoid biosynthesis, PSY, LCYB, and LCYE, and compared the $\mathrm{Y}_{2}$ loci, but no difference was found between wild and cultivated carrots. Therefore, we concluded that the reported results (Braden et al. 1998; Lipinski et al. 2002) are true only for specific varieties investigated by the researchers.

The big difference in $\alpha$-carotene content between the wild, hybrid and cultivated carrots was a likely promising clue for finding useful gene markers (Figure 3). Transcription factors that are possibly in charge of controlling the expression of $L C Y E$ are a candidate marker. In order to identify genes that control carotene content in taproot, further analysis is needed such as on the expression of these genes and downstream/upstream products of carotene.

We also tested AFLP analysis using the 30 AFLP primer combinations that can produce polymorphic bands in carrot (Shim et al. 2000). Fragments obtained by AFLP were scored as present (1) or absent (0) and recorded in a data matrix (Table 1). A parameter of gene diversity, heterozygosity was calculated following Nei's heterozygosity (1973) using POPGENE software (available at URL https://www.unalberta.ca/ fyeh). Ten AFLP primer combinations were used to analyze the gene diversity of wild and cultivated carrots, and 997 reproducible bands were produced. Among them, 979 bands (98.2\%) were polymorphic. The number of polymorphic bands varied from 69 to 209 per one primer set. The numbers of bands in wild and cultivated carrots were 73.1 and 78.8 on average, respectively. The percentage of polymorphic bands obtained from cultivated carrot $(90.9 \%)$ was almost same as that of wild carrot (90.1\%). Heterozygosity of cultivated carrot was 0.236, and was smaller than that of wild carrot, 0.250 .

From a primer set of E-AGG/M-CTG, fragments that can highly distinguish wild from cultivated carrot were obtained (Table 1). Fragments ranging from $450 \mathrm{bp}$ to $500 \mathrm{bp}$ in length were found only but in $95 \%$ of the cultivated carrots, and a $550 \mathrm{bp}$ fragment was detected only in wild carrot. A $457 \mathrm{bp}$ fragment from paternal cultivated carrot was found in $50 \%$ of the hybrid. A 
Table 1. An example of AFLP fragment data of a primer set of E-AGG/M-CTG.

\begin{tabular}{|c|c|c|c|c|c|c|c|c|c|c|c|c|c|c|c|c|c|c|c|c|}
\hline $\begin{array}{c}\text { Fragment size } \\
\text { (bp) }\end{array}$ & $\because \mathrm{C} 1$ & $\mathrm{C} 2$ & $\mathrm{C} 3$ & $\mathrm{C} 4$ & C5 & C6 & $\mathrm{C} 7$ & $\mathrm{C} 8$ & C9 & C10 & ${ }^{* W 1}$ & W2 & W3 & W4 & W5 & W6 & W7 & W8 & W9 & W10 \\
\hline 80 & 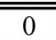 & 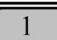 & $\bar{~} 1$ & 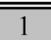 & 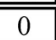 & 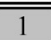 & $\overline{0}$ & 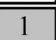 & 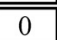 & 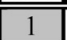 & $\overline{0}$ & 0 & $\overline{1}$ & 1 & 1 & 0 & 0 & 0 & $\overline{0}$ & $\overline{1}$ \\
\hline 84 & 0 & 1 & 1 & 1 & 1 & 1 & 0 & 1 & 1 & 1 & 0 & 1 & 1 & 1 & 1 & 1 & 0 & 0 & 1 & 1 \\
\hline 86 & 0 & 1 & 1 & 0 & 0 & 0 & 0 & 0 & 0 & 0 & 1 & 1 & 1 & 1 & 1 & 0 & 1 & 1 & 1 & 1 \\
\hline 91 & 0 & 0 & 0 & 0 & 0 & 0 & 0 & 0 & 0 & 0 & 0 & 0 & 0 & 1 & 0 & 0 & 0 & 0 & 0 & 0 \\
\hline 94 & 0 & 0 & 0 & 0 & 0 & 0 & 0 & 0 & 0 & 0 & 1 & 0 & 0 & 1 & 0 & 0 & 0 & 0 & 0 & 0 \\
\hline 113 & 0 & 0 & 0 & 0 & 0 & 0 & 0 & 1 & 0 & 0 & 1 & 1 & 0 & 0 & 1 & 0 & 0 & 0 & 0 & 1 \\
\hline 117 & 1 & 1 & 1 & 0 & 0 & 0 & 0 & 0 & 1 & 1 & 0 & 0 & 1 & 0 & 0 & 1 & 0 & 0 & 0 & 0 \\
\hline 122 & 0 & 0 & 0 & 0 & 0 & 0 & 0 & 0 & 0 & 0 & 0 & 0 & 0 & 0 & 0 & 0 & 0 & 1 & 0 & 0 \\
\hline 125 & 0 & 1 & 0 & 1 & 1 & 0 & 0 & 0 & 0 & 0 & 0 & 1 & 0 & 0 & 0 & 0 & 0 & 0 & 0 & 0 \\
\hline 127 & 0 & 1 & 1 & 0 & 0 & 1 & 0 & 1 & 1 & 1 & 0 & 1 & 1 & 1 & 1 & 0 & 0 & 0 & 0 & 1 \\
\hline 131 & 0 & 0 & 0 & 1 & 0 & 0 & 0 & 0 & 0 & 0 & 0 & 0 & 0 & 0 & 1 & 0 & 0 & 0 & 0 & 1 \\
\hline 133 & 0 & 0 & 0 & 0 & 0 & 0 & 0 & 0 & 0 & 0 & 0 & 0 & 0 & 1 & 1 & 0 & 0 & 0 & 0 & 0 \\
\hline 137 & 1 & 1 & 0 & 1 & 1 & 1 & 1 & 0 & 0 & 0 & 1 & 0 & 0 & 1 & 1 & 0 & 1 & 1 & 0 & 0 \\
\hline 146 & 0 & 0 & 0 & 0 & 0 & 0 & 0 & 0 & 0 & 0 & 0 & 0 & 0 & 1 & 0 & 0 & 0 & 0 & 0 & 0 \\
\hline 149 & 0 & 1 & 0 & 0 & 1 & 1 & 1 & 0 & 1 & 0 & 1 & 0 & 0 & 0 & 0 & 0 & 1 & 0 & 0 & 0 \\
\hline 153 & 0 & 0 & 0 & 0 & 0 & 0 & 0 & 0 & 0 & 0 & 0 & 0 & 1 & 0 & 0 & 1 & 0 & 1 & 1 & 0 \\
\hline 154 & 0 & 0 & 0 & 0 & 0 & 0 & 0 & 0 & 0 & 0 & 0 & 1 & 1 & 0 & 1 & 1 & 0 & 1 & 1 & 0 \\
\hline 165 & 0 & 1 & 1 & 1 & 1 & 1 & 1 & 1 & 1 & 1 & 1 & 1 & 1 & 1 & 1 & 1 & 1 & 1 & 1 & 1 \\
\hline 176 & 0 & 0 & 0 & 0 & 0 & 1 & 0 & 0 & 0 & 0 & 1 & 0 & 1 & 1 & 1 & 1 & 1 & 0 & 1 & 1 \\
\hline 177 & 1 & 0 & 0 & 0 & 0 & 0 & 0 & 1 & 0 & 0 & 1 & 1 & 1 & 0 & 1 & 1 & 1 & 1 & 1 & 1 \\
\hline 181 & 0 & 0 & 0 & 0 & 0 & 0 & 0 & 0 & 0 & 0 & 0 & 0 & 0 & 1 & 0 & 0 & 0 & 0 & 0 & 0 \\
\hline 183 & 0 & 0 & 0 & 0 & 0 & 0 & 0 & 0 & 0 & 0 & 0 & 0 & 0 & 1 & 0 & 0 & 0 & 0 & 0 & 1 \\
\hline 184 & 0 & 1 & 0 & 1 & 0 & 0 & 1 & 0 & 1 & 0 & 0 & 1 & 1 & 1 & 1 & 1 & 1 & 1 & 1 & 1 \\
\hline 185 & 1 & 1 & 1 & 1 & 1 & 1 & 1 & 1 & 0 & 1 & 1 & 1 & 1 & 1 & 1 & 1 & 1 & 1 & 1 & 1 \\
\hline 188 & 0 & 0 & 0 & 0 & 0 & 0 & 0 & 0 & 1 & 0 & 0 & 0 & 0 & 0 & 0 & 0 & 0 & 0 & 1 & 0 \\
\hline 190 & 1 & 1 & 1 & 1 & 1 & 1 & 1 & 0 & 0 & 1 & 1 & 1 & 1 & 1 & 1 & 1 & 1 & 1 & 1 & 1 \\
\hline 193 & 0 & 0 & 0 & 0 & 0 & 0 & 0 & 0 & 1 & 0 & 0 & 1 & 0 & 0 & 0 & 0 & 0 & 0 & 0 & 0 \\
\hline 194 & 0 & 0 & 1 & 0 & 1 & 1 & 0 & 0 & 0 & 0 & 0 & 1 & 1 & 1 & 1 & 1 & 0 & 1 & 0 & 1 \\
\hline 203 & 0 & 0 & 0 & 1 & 1 & 0 & 0 & 1 & 0 & 0 & 1 & 1 & 1 & 1 & 1 & 1 & 1 & 1 & 1 & 1 \\
\hline 205 & 0 & 0 & 0 & 0 & 0 & 0 & 0 & 0 & 0 & 0 & 0 & 0 & 1 & 1 & 0 & 0 & 1 & 0 & 0 & 1 \\
\hline 207 & 0 & 0 & 0 & 0 & 0 & 0 & 0 & 0 & 1 & 0 & 1 & 1 & 0 & 0 & 0 & 0 & 0 & 0 & 0 & 0 \\
\hline 208 & 1 & 1 & 1 & 1 & 1 & 1 & 1 & 1 & 0 & 1 & 1 & 1 & 0 & 1 & 0 & 1 & 1 & 1 & 1 & 0 \\
\hline 238 & 0 & 0 & 0 & 1 & 0 & 0 & 0 & 0 & 0 & 0 & 0 & 0 & 0 & 0 & 0 & 0 & 0 & 0 & 0 & 0 \\
\hline 250 & 0 & 0 & 0 & 0 & 0 & 0 & 0 & 0 & 0 & 0 & 0 & 1 & 1 & 1 & 0 & 1 & 1 & 0 & 1 & 1 \\
\hline 256 & 0 & 0 & 0 & 0 & 0 & 0 & 0 & 0 & 0 & 0 & 0 & 0 & 0 & 1 & 0 & 0 & 0 & 0 & 0 & 0 \\
\hline 266 & 0 & 0 & 1 & 1 & 1 & 1 & 1 & 1 & 1 & 1 & 1 & 1 & 0 & 1 & 1 & 0 & 0 & 0 & 0 & 0 \\
\hline 270 & 0 & 0 & 0 & 0 & 0 & 0 & 0 & 0 & 0 & 0 & 1 & 0 & 0 & 1 & 0 & 0 & 0 & 0 & 0 & 0 \\
\hline 281 & 1 & 1 & 1 & 1 & 1 & 0 & 0 & & 0 & 0 & 0 & 0 & 0 & 1 & 0 & 1 & 0 & 1 & 1 & 1 \\
\hline 282 & 0 & 0 & 0 & 0 & 0 & 0 & 0 & 0 & 1 & 0 & 0 & 0 & 0 & 0 & 0 & 0 & 0 & 0 & 0 & 0 \\
\hline 283 & 1 & 1 & 1 & 1 & 1 & 1 & 1 & 1 & 1 & 1 & 1 & 1 & 1 & 1 & 1 & 1 & 1 & 1 & 1 & 1 \\
\hline 340 & 0 & 1 & 1 & 1 & 1 & 1 & 1 & 0 & 0 & 1 & 1 & 1 & 0 & 1 & 1 & 1 & 1 & 1 & 0 & 1 \\
\hline 341 & 0 & 0 & 0 & 0 & 0 & 0 & 0 & 0 & 0 & 0 & 0 & 1 & 1 & 0 & 1 & 1 & 1 & 1 & 1 & 0 \\
\hline 342 & 0 & 0 & 0 & 0 & 0 & 0 & 0 & 0 & 1 & 0 & 0 & 0 & 0 & 0 & 0 & 0 & 0 & 0 & 0 & 0 \\
\hline 356 & 0 & 0 & 0 & 0 & 0 & 1 & 0 & 0 & 1 & 0 & 0 & 0 & 0 & 0 & 0 & 0 & 0 & 0 & 0 & 0 \\
\hline 366 & 0 & 0 & 0 & 0 & 0 & 0 & 0 & 0 & 0 & 0 & 0 & 0 & 0 & 1 & 0 & 0 & 0 & 0 & 0 & 0 \\
\hline 371 & 1 & 0 & 0 & 1 & 0 & 0 & 0 & 0 & 1 & 0 & 0 & 0 & 0 & 0 & 0 & 0 & 0 & 0 & 0 & 0 \\
\hline 405 & 0 & 1 & 0 & 1 & 0 & 0 & 0 & 0 & 1 & 0 & 0 & 0 & 1 & 0 & 1 & 1 & 0 & 0 & 0 & 0 \\
\hline 407 & 1 & 0 & 1 & 0 & 1 & 1 & 1 & 1 & 0 & 1 & 0 & 0 & 1 & 0 & 0 & 1 & 0 & 0 & 0 & 0 \\
\hline 454 & 0 & 0 & 0 & 0 & 0 & 0 & 0 & 0 & 1 & 0 & 0 & 0 & 0 & 0 & 0 & 0 & 0 & 0 & 0 & 0 \\
\hline 457 & 1 & 1 & 1 & 1 & 1 & 0 & 0 & 0 & 0 & 0 & 0 & 0 & 0 & 0 & 0 & 0 & 0 & 0 & 0 & 0 \\
\hline 463 & 0 & 0 & 0 & 0 & 0 & 1 & 0 & 1 & 0 & 1 & 0 & 0 & 0 & 0 & 0 & 0 & 0 & 0 & 0 & 0 \\
\hline 494 & 1 & 0 & 1 & 0 & 1 & 0 & 1 & 1 & 0 & 0 & 0 & 0 & 0 & 0 & 0 & 0 & 0 & 0 & 0 & 0 \\
\hline 495 & 0 & 1 & 0 & 1 & 0 & 0 & 0 & 0 & 1 & 0 & 0 & 0 & 0 & 0 & 0 & 0 & 0 & 0 & 0 & 0 \\
\hline $\mathbf{5 5 0}$ & 0 & 0 & 0 & 0 & 0 & 0 & 0 & 0 & 0 & 0 & 1 & 1 & 1 & 1 & 1 & 1 & 1 & 1 & 1 & 1 \\
\hline
\end{tabular}

* $\mathrm{C}$ and $\mathrm{W}$ denote cultivated and wild carrot, respectively. 0 and 1 show the absence and presence of the fragment, respectively. $283 \mathrm{bp}$ fragment was common in the wild and cultivated carrots. $550 \mathrm{bp}$ and $454-495 \mathrm{bp}$ fragments were specific to the wild and cultivated carrots, respectively.

$550 \mathrm{bp}$ fragment from the maternal wild carrot was observed in $30 \%$ of the hybrid.

In AFLP analysis, specific fragments that could distinguish wild from cultivated carrot were found. AFLP, which has high sensitivity, was found to be useful to examine differences between populations of a same species. However, AFLP markers have dominant traits and were difficult to trace through all the hybrids. Therefore, we should also find co-dominant markers in addition to these AFLP markers.

This series of studies showed that gene flow from GM carrots has effects that cannot be ignored on the gene 
diversity of their wild relatives. AFLP analysis revealed that carrots, even cultivated varieties, have extremely wide gene diversity compared to other plants. For example, Arabidopsis thaliana has a heterozygosity of only 0.135 , and its proportion of polymorphic band is only $60 \%$ (Jogensen et al. 2004). From all the studies carried out in this work, including those on population density, pollination distance, and seed scattering, gene flow seems to occur between populations of wild carrot. In order to prove it, further studies on gene diversity of various populations are needed.

\section{Conclusion}

In this study, various traits of wild carrot were revealed. However, the study could not reveal the effects of gene flow from GM crops to their wild relatives. Actually, some transgenes of GM crops, such as insect-resistance, give ecologically superior traits to the plants, and hybrids between GM crops and their wild relatives possibly become advantageous over wild plants, driving away the wild relatives and other plants and causing gene diversity to be lost. After all, the ecological superiority of each transgene in each plant needs to be investigated.

The best way to investigate the environmental effects might be growing GM crops. However, there are no GM crops suitable for environmental studies in Japan. Therefore, an experimental system that can monitor transitions in gene diversity by introgression should be constructed using carrot. This monitoring system will be an effective model for predicting the effect of GM crops on their wild relatives and will contribute to the construction of a guideline for assessing environmental effects of GM crops.

\section{Acknowledgements}

We are grateful to Dr. Y. Toquenaga of University of Tsukuba for kindly developing the software for analyzing insects' behaviors, and Mr. T. Takagi of Kyowa Seed Co., Ltd. for kindly providing cultivated carrot (cv. Kurodagosun). We are grateful to Prof. H. Takahashi of the Hokkaido University Museum for the first description of wild carrot in Hokkaido. This work was supported, in part, by a Grant-in-Aid from the Research for the Future Program of the Japan Society for the Promotion of Science (JSPSRFTF00L01601)

\section{References}

Bohart GE, Nye WP (1960) Insect pollination of carrot in Uta. Uta Agr Expt Sta Bul 419: 1-16

Borthwick HA, Emsweller SL (1933) Carrot breeding experiments. Proc Am Soc Hort Sci 30: 531-533

Bradeen JM, Simon PW (1998) Conversion of an AFLP fragment linked to the carrot $Y_{2}$ locus to a simple, codominant, PCR-based marker form. Theor Appl Genet 97: 960-967
Brandenburg WA (1981) Possible relationships between wild and cultivated carrot (Daucus carota L.) in the Netherlands. Kulturpflanze 29: 369-375

Buishand JG, Gabelman WH (1979) Investigations on the inheritance of color and carotenoid content in phloem and xylem of carrot roots (Daucus carota L.). Euphytica 28: 611-632

Chase MR, Moller C, Kesseli R, Bawa KS (1996) Distant gene flow in tropical trees. Nature 383: 398-399

Conner AJ, Glare TR, Nap J (2003) The release of genetically modified crops into the environment-Part II. Overview of ecological risk assessment. Plant J 33: 19-46

Dale HM (1974) The biology of Canadian weeds. 5. Daucus carota. Can J Plant Sci 54: 673-685

Eguchi I, Umehara M, Ono M, Kamada H (2004) Proposals to investigate gene flow and gene diversity using carrot (Daucus carota L.). In: Kim S (ed) GM crops and Foods-Potential Safety and Environmental Impact. The Korean Federation of Science and Technology Societies (KOFST) Seoul, Korea, pp 69-82

Frankton C, Mulligan GA (1970) Weeds of Canada. Queen's Printer, Ottawa, Ontario, p 217

Galuszka H, Torek K, Goral M (1989) Studies of pollination by bees (Apis mellifera L.). Biuletyn Warzwniczy 33: 35-58

Georgia AE (1914) A Manual of Weeds. Macmillan Co., New York, p 593

Hawthorn LR, Bohart GE, Toole EH (1956) Carrot seed yield and germination as affected by different levels of insect pollination. Proc Am Soc Hort Sci 67: 384-389

Hawthorn LR, Bohart GE, Toole EH, Nye WP, Levin MD (1960) Carrot seed production as affected by insect pollination. Uta Agr Expt Sta Bul 422: 1-18

Isagi Y, Kanazashi T, Suzuki W, Tanaka H, Abe T (2000) Microsatellite analysis of the regeneration process of Magnolia obovata Thumb. Heredity 84: 143-151

Jøgensen S, Mauricio R (2004) Neutral genetic variation among wild North American populations of the weedy plant Arabidopsis thaliana is not geographically structured. Mol Ecol 13: 3403-3413

Koga S, Namai H (2001) Effect of wind direction of pollen flow depending on insect pollinators in carrot (Daucus carota $\mathrm{L}$.) $\mathrm{F}_{1}$ seed production. Breed Res 3: 81-86 (In Japanese)

Miyazaki Y, Isagi Y (2000) Pollen flow and the intrapopulation genetic structure of Heloniopsis orientalis on the forest floor as determined using microsatellite markers. Theor Appl Genet 101: 718-723

Nakajima Y, Yamamoto T, Oeda K (1997) Genetic variation of mitochondrial and nuclear genomes in carrots revealed by random amplified polymorphic DNA (RAPD). Euphytica 95: 259-267

Nakajima Y, Oeda K, Yamamoto T (1998) Characterization of genetic diversity of nuclear and mitochondrial geneomes in Daucus varieties by RAPD and AFLP. Plant Cell Rep 17: $848-853$

Nap J, Metz PLJ, Escaler M, Conner AJ (2003) The release of genetically modified crops into the environment-Part I. Overview of current status and regulations. Plant J 33: 1-18

Nei M (1973) Analysis of gene diversity in subdivided populations. Proc Natl Acad Sci USA 70: 3321-3323

Perlak FJ, Oppenhuizen M, Gustafson K, Voth R, Sivasupramaniam S, Heering D, Carey B, Ihrig RA, Roberts JK (2001) Development and commercial use of Bollgard ${ }^{\circledR}$ cotton in the USA - early promises versus today's reality. Plant $J 27$ : 489-501 
Peterson CE, Simon PW (1986) Carrot breeding. In: Basset MJ (ed) Breeding Vegetable Crops, AVI Pubrishing Co. Inc, Conn., pp 321-356

Quist D, Chapela IH (2001) Transgenic DNA introgressed into traditional maize landraces in Oaxaca, Mexico. Nature 414: $541-543$

Shelton AM, Sears MK (2001) The monarch butterfly controversy: scientific interpretations of a phenomenon. Plant $J 27$ : 483-488

Shim SI, Jørgensen RB (2000) Genetic structure in cultivated and wild carrots (Daucus carota L.) revealed by AFLP analysis. Theor Appl Getet 101: 227-233

Simon PW (1996) Inheritance and expression of purple and yellow storage root color in carrot. J Hered 87: 63-66

Snow AA, Palma PM (1997) Commercialization of transgenic plants: potential ecological risks. Bioscience 47: 86-96

Stachler JM, Kells JJ (1997) Wild carrot (Daucus carota) control in no-tillage cropping systems. Weed Technol 11: 444-452

Stachler JM, Kells JJ, Penner D (2000) Resistance of wild carrot (Daucus carota) to 2,4-D in Michigan. Weed Technol 14: 734739

Streiff R, Ducousso A, Lexer C, Steinkellner H, Gloessl J, Kremer
A (1999) Pollen dispersal inferred from paternity analysis in a mixed oak stand of Quercus robur L. and Q. petraea (Matt.) Liebl. Mol Ecol 8: 831-841

Sylwester EP (1960) Beware of wild carrot. Hoard's Dairyman 105: $330-331$

Thompson DJ (1962) Natural cross-pollination in carrots. Proc Am Soc Hort Sci 81: 332-334

Vos P, Hogers R, Bleeker M, Reijans M, van de Lee, T, Hornes M, Frijters A, Pot J, Peleman J, Kuiper M, Zabeau M (1995) AFLP: a new technique for DNA fingerprinting. Nucl Acids Res 23: $4407-4414$

Welsh J, McClelland M (1990) Fingerprinting genomes using PCR with arbitrary primers. Nucl Acids Res 18: 7213-7218

Wijnheijmer EHM, Brandenburg WA, Ter Borg SJ (1989) Interactions between wild and cultivated carrots (Daucus carota L.) in the Netherlands. Euphytica 40: 147-154

Williams JGK, Kubelik AR, Livak KJ, Rafalski JA, Tingey SV (1990) DNA polymorphisms amplified by arbitrary primers are useful as genetic markers. Nucl Acids Res 18: 6531-6535

Yamamoto T, Nishikawa A, Oeda K (1994) DNA polymorphisms in Oryza sativa L. and Lactuca sativa L. amplified by arbitrary primed PCR. Euphytica 78: 143-148 